\title{
Spatial Utilization Coordination Features and Development Potential on Ecology-Agriculture-Urban Space of Key Ecological Function Areas: A Case Study of Tacheng Basin, China
}

\author{
Guiling Wang ${ }^{1,2}$, Degang Yang ${ }^{2}$, Lei Ye ${ }^{1 *}$, Chuanhe Xiong ${ }^{3}$ \\ ${ }^{1}$ School of Geographic Science, Nantong University, Nantong, China \\ ${ }^{2}$ Xinjiang Institute of Ecology and Geography, Chinese Academy of Sciences, Urumqi, China \\ ${ }^{3}$ Key Laboratory of Watershed Geographic Sciences, Nanjing Institute of Geography and Limnology, \\ Chinese Academy of Sciences, Nanjing, China
}

Received: 25 October 2019

Accepted: 2 February 2020

\begin{abstract}
It is very necessary to promote the construction of key ecological function areas to protect national ecological security because of its relatively fragile ecosystem and important ecological value. From the perspective of ecology-agriculture-urban space, this study aims to make dynamic comparative analysis of the coordinated development levels between 2008 and 2018, and explore the characteristics of spatial utilization, existing problems and the potential of development in Tacheng Basin. The results indicate that:

1) The coupling coordination degree of ecology-agriculture-urban space in Tacheng Basin is still in low-level state. However, there exist some disparities between 2008 and 2018. The maximum value is only 0.434 in 2008 and it increases to 0.492 in 2018.

2) The ecology-agriculture-urban space of Tacheng Basin has greater development potential with the characteristics of spatial agglomeration distribution. Ecological, agricultural and urban spaces are interconnected and interact with each other, but the emphasis on developmental direction is different with respective characteristic resources.

3) Regional interconnectivity and integration development is an effective way to realize the coordinated development of ecology-agriculture-urban space. Therefore, according to the analytical results and advantages for development, we have proposed corresponding policy recommendations
\end{abstract}

*e-mail: yelei@ntu.edu.cn 
from the perspective of ecological protection, economic transformation and regional division and cooperation.

Keywords: ecology-agriculture-urban space, spatial coupling degree, coordination development, Tacheng Basin

\section{Introduction}

The two core issues in the field of world sustainable development are to eliminate poverty and protect the ecological environment [1]. With the development of industrialization and urbanization, the phenomenon of neglecting the environmental bearing capacity and decrease of cultivated land and ecological land year by year exists in different regions, and food security and ecological security are seriously threatened, which has become a universal problem faced by the whole world [2]. Especially for some ecologically fragile areas, increasing consumption and destruction of resources and the environment make the natural ecosystem lose restoration capacity and the basic conditions for sustainable development [3, 4]. With continuous expansion of urban and rural construction land, the contradiction among urban space, agricultural space and ecological space is further intensified, and agricultural space and ecological space are squeezed. There are sharp contradictions between economic development and ecological protection, urban development and agricultural production, which have become the main bottleneck blocking the full exertion of regional advantage and enhancement of competitiveness. Based on this background, it is necessary to rationally allocate spatial resources, scientifically handle the relationship between protection and development, and promote healthy and sustainable development of ecologyagriculture-urban space.

Ecology-agriculture-urban space is short for ecological space, agricultural space and town space, which corresponds to the ecological, agricultural and urban patterns proposed in the strategy of functional zones. It emphasizes the determination of functional positioning and development mode according to the bearing capacity of resources and the environment in different regions so as to improve development and protection policies and standardize the development order [5]. Some scholars have discussed the concept of "three types of space". They think that urban space is an important population and economic agglomeration area responsible for urban construction and economic development; agricultural space mainly ensures national food security and building new countryside [6]; and ecological space undertakes the functions of ecological service, ecosystem maintenance and promoting harmonious development of people and nature [7]. At the same time, relevant scholars also have discussed spatial divisions and patterns. Based on the positioning of main functions, after comprehensive evaluation of various indicators, three types of spaces were divided according to the current situation of regional development. Generally speaking, they made overlay analysis of evaluation results with the current surface to form the suitability evaluation of spatial development combined with repeated verification of remote sensing image interpretation and field survey, finally dividing three types of space [8]. Viegas and Antunes put forward suggestions conducive to regional coordination and sustainable development [9]. In addition, some also used methods of spatial overlay and spatial statistics to evaluate spatial development suitability, and studied spatial pattern and spatial zoning governance based on the identification results [10]. Therefore, scientific recognition of ecology-agriculture-urban space makes the implementation of the national spatial planning path clearer. We should pay more attention to the dynamic management of the ecology-agriculture-urban space according to the requirements of space development and space control, timely adjusting the spatial scope, policy measures and implementation path of key ecological functional areas.

The ecosystem of key ecological functional areas is relatively fragile and undertakes important ecological functions $[11,12]$. It is very important to promote the construction of such areas in order to protect national ecological security [13]. In recent years, domestic scholars have focused on the research of spatial evaluation, ecological compensation, space development and ecological protection about key ecological function areas [14]. Some researchers have explored the subdivision of spatial functional areas by constructing a multi-index evaluation index system and using the spatial evaluation method, and proposed corresponding evaluation mode and development suggestions $[15,16]$. Based on the perspective of industrial development, a small group of scholars analyzed the economic effect of ecological compensation in key ecological function areas, and the consistency of selection criteria between superior industries and featured superior industries, and proposed feasible development suggestions in the future $[17,18]$. In addition, some research focused on the ecological assessment [19], urbanization level and spatial pattern of key ecological function areas [20, 21]. Abroad, Bailey, an American scholar, first proposed ecological zoning, and summarized and sorted the grading system of ecological zones. However, most researchers concentrated on evaluating the fragile ecosystem [22], the fragility of a tourism society ecosystem [23], and the carrying capacity of an ecosystem [24]. Furthermore, Carranza and Manica studied the mismatch between management evaluation and conservation results of nature reserve in Brazil 
[25]. Based on the analysis of tourists' willingness to pay in Annapurna Peak Nature Reserve in Nepal, Baral and Dhungana concluded that the key to improving the effectiveness of biodiversity conservation is to maintain financial supply in this area [26]. These views centered on exploration of regional nature reserves and identification methods for different types of regions [27].

As mentioned above, the majority have focused on the division of three types of space, evaluating spatial patterns and exploring the development mode without a comparative analysis of coordinated development of ecology-agriculture-urban space utilization. For a key ecological function area, due to topographic conditions, the ecological zones used for agricultural production and urban development are much smaller than those of ecological space. Once ecological space is destroyed, agricultural space and urban space will be greatly affected, and the contradiction between space development and protection is more prominent. Therefore, it is more important and meaningful to study spatial utilization coordination features and development potential in key ecological function zones based on ecology-agriculture-urban space.

This article aims to make dynamic comparative analysis of the coordinated development level between 2008 and 2018, and explore the characteristics of space utilization, existing problems and the potential for development. It points out the importance of improving the coordinated development level of ecology-agriculture-urban space due to its significance in optimizing the ecological environment, raising industrial development levels and improving the quality of life in urban areas and the fact that this is the most underreported problem, which is difficult to solve in Tacheng Basin.

\section{Materials and Methods}

\section{Description of Study Area}

Tacheng Basin is located in northwest Xinjiang Uygur Autonomous Region in China, and bounded on the northwest by Kazakhstan. Its geographical extent is $44^{\circ} 58^{\prime} \mathrm{N}-47^{\circ} 14^{\prime} \mathrm{N}$ and $82^{\circ} 12^{\prime} \mathrm{E}-85^{\circ} 20^{\prime} \mathrm{E}$, which features a temperate continental arid climate and the second largest grassland in China: Kulusitai Grassland. This region includes one city and three counties: Tacheng city and Emin, Yumin, and Tuoli counties. It covers an area of approximately $47,744 \mathrm{~km}^{2}$. Over the past decade, Tacheng Basin has demonstrated a remarkably fast rate of growth. The basin has a population of 0.53 million people, and its gross domestic product has increased to 21.84 billion yuan (Fig. 1). Although it is realizing rapid social and economic progress, the overall development of urbanization and industrialization remains at a low level. In recent years, influenced by the natural environment and human factors, Tacheng Basin is facing severe ecological crises. There is disordered

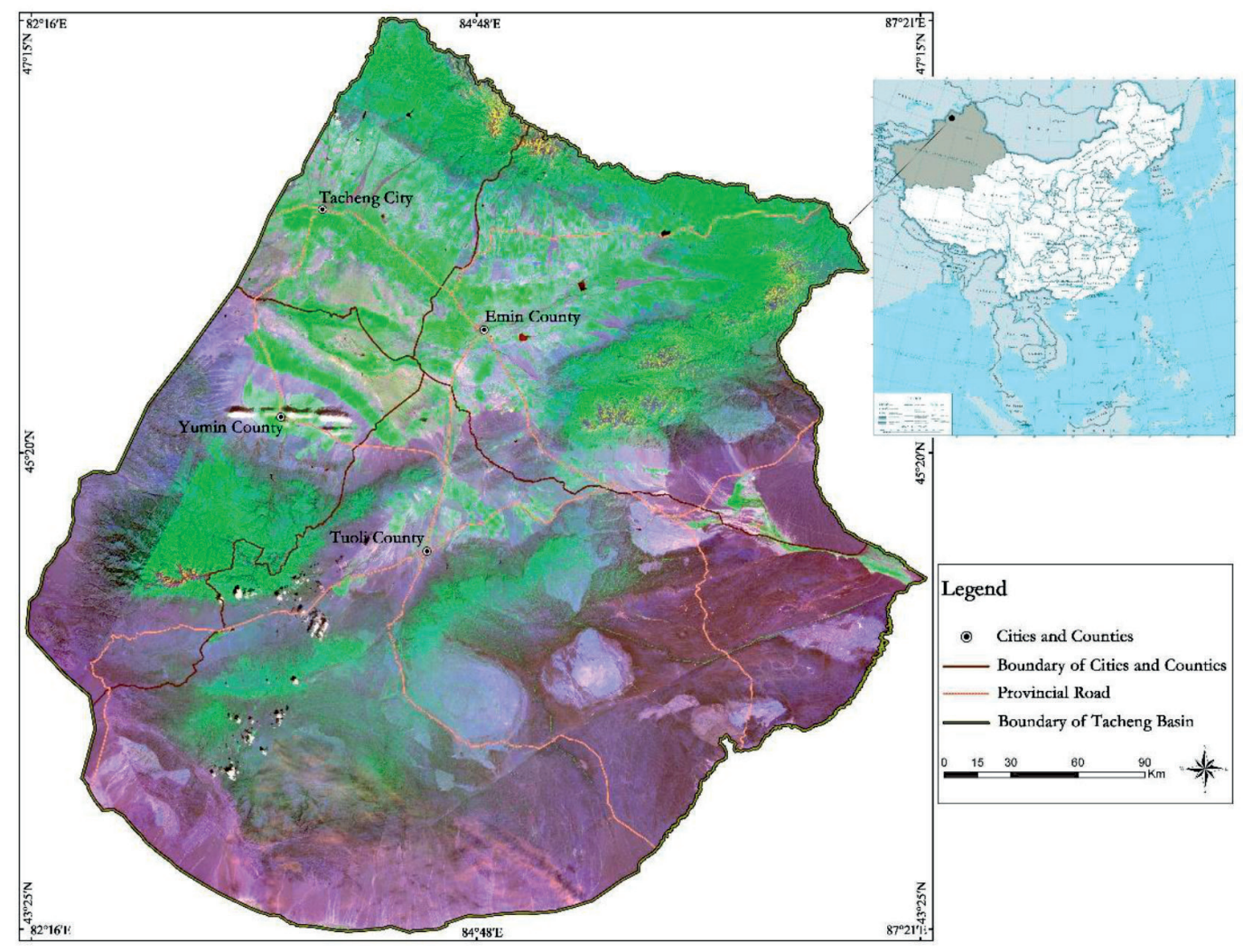

Fig. 1. Location of Tacheng Basin. 
production activity in the space, resulting in decreasing total ecological land and increasing pressure on urban ecological resources. These factors exacerbate the problems of low economic development and coordinated development in Tacheng Basin.

\section{The Method of Evaluation Index System Construction}

Spatial coordination degree is a relative index used to measure the positive coupling degree within and among ecological, agricultural and urban spaces for a certain region at different times. The coordination degree index system should be first constructed before the evaluation of spatial coordination degree. According to "the ecological function zoning interim procedures", "the regulations and technology of main body function zoning at the provincial level" issued by the Ministry of the Environment, and "the technical specifications and guidelines for the establishment of multi-regulation" issued by the National Development and Reform Commission, at the same time, combined with the main function orientation and development status of Tacheng Basin, this study established a multi-index evaluation system used to evaluate the coordination degree from the perspective of ecological space protection level, agricultural space utilization level and urban space development level (Table 1).

\section{The Coupling Coordination Degree Model}

In this paper, the multi-factor comprehensive evaluation model is used to calculate the index of ecological space protection, the index of agricultural space utilization and the index of urban space development. Because the common factors are independent, the variance contribution rate is used as the weight. The specific calculation formula is as follows:

$$
\begin{array}{r}
E=\sum_{k=1}^{m}\left(e_{k} \times X_{i k}\right) \\
A=\sum_{k=1}^{m}\left(a_{k} \times X_{i k}\right) \\
U=\sum_{k=1}^{m}\left(t_{k} \times X_{i k}\right)
\end{array}
$$

...where E, A and $\mathrm{U}$ are respectively the order parameters composed of common factors including ecological space, agricultural space and urban space; $\mathrm{e}_{\mathrm{k}}$ is the variance contribution rate of the $\mathrm{k}$-th common factor of ecological space evaluation index system $a_{k}$ is of ecological space evaluation index system, and $t_{k}$ is of urban space evaluation index system; $\mathrm{X}_{\mathrm{ik}}$ is the k-th common factor of class i space.

The coupling coefficient is adopted to measure the tightness degree of coupling between circuits in physics, and the coupling coefficient between circuits is generally expressed by the capacitance coupling formula [28]. If this formula is extended to express the coupling degree of ecological space, agricultural space and urban space, the expression formula is as follows:

$$
C=2\{(e \times a \times t) /[(e+a)(e+t)(a+t)]\}^{1 / 3} \quad C \in[0,1]
$$

...where $\mathrm{C}$ is the coefficient of coupling degree, and

\begin{tabular}{|c|c|c|}
\hline Objective level & Index level & Basic levels \\
\hline \multirow{3}{*}{$\begin{array}{l}\text { Ecological space } \\
\text { protection level }\end{array}$} & Status of natural resources & $\begin{array}{c}\text { Elevation(X1); Slope(X2); Annual rainfall(X3); Per capita available } \\
\text { land area(X4) }\end{array}$ \\
\hline & Ecological environment vulnerability & Soil erosion(X5); Land desertification(X6); Vegetation coverage(X7) \\
\hline & Importance of ecological function & $\begin{array}{c}\text { Importance of water conservation(X8); Importance of biodiversity } \\
\text { maintenance(X9) }\end{array}$ \\
\hline \multirow{3}{*}{$\begin{array}{l}\text { Agricultural space } \\
\text { utilization level }\end{array}$} & Agricultural input level & $\begin{array}{l}\text { Pesticide usage(X10); Fertilizer use(X11); Electricity consumption for } \\
\text { agricultural production(X12); Rural labor force(X13); Proportion of } \\
\text { available irrigation area(X14) }\end{array}$ \\
\hline & Ecological product supply potential & $\begin{array}{l}\text { Supply potential of green agricultural products(X15); Ecotourism } \\
\text { Product(X16) }\end{array}$ \\
\hline & Rural development level & Gross farm production(X17); Farmers' per capita income(X18) \\
\hline \multirow{2}{*}{$\begin{array}{c}\text { Urban space } \\
\text { development level }\end{array}$} & $\begin{array}{l}\text { Status quo of urbanization } \\
\text { development }\end{array}$ & $\begin{array}{l}\text { Population urbanization rate(X19); Urban construction land } \\
\text { area(X20); Population density(X21) }\end{array}$ \\
\hline & Urban service level & $\begin{array}{c}\text { Traffic density(X22); Infrastructure perfection (X23); Health care } \\
\text { coverage(X24) }\end{array}$ \\
\hline
\end{tabular}
$\mathrm{e}$, a and $\mathrm{t}$ have the same meanings as those in Eqs. (1-3). If $\mathrm{C}=0$, it means that the coupling degree between

Table 1. Evaluation index system of ecology-agriculture-urban space coordination development in Tacheng Basin. 
systems is small and basically in an extraneous state and the system will turn to disorder development; if $\mathrm{C}=1$, it indicates that the system tends to be in a benign resonance coupling state, and the system will turn to a new ordered structure.

In this paper, a coupling coordination degree model is constructed to analyze the level of coupling coordination development between ecological space, agricultural space and urban space of each unit. The formula is as follows:

$$
\begin{gathered}
D=(C \times T)^{1 / a} \quad T=a E+b A+c U \quad D \in[0,1] \\
T \in(0,1)
\end{gathered}
$$

...where $\mathrm{D}$ is the coefficient of coordinated development, and the larger the value is, the higher the degree of coordination; $\mathrm{T}$ is the comprehensive harmonic index of ecological space, agricultural space and urban space, which reflects the synergistic development effect among three types of space; and $\mathrm{a}, \mathrm{b}$ and $\mathrm{c}$ are undetermined coefficients $(\mathrm{a}+\mathrm{b}+\mathrm{c}=1)$. Because $\mathrm{a}, \mathrm{b}$ and $\mathrm{c}$ are of equal importance, the values in this paper are all $1 / 3$. According to the relevant studies [29], the coefficient of coordinated development (D) in this paper is $0.4,0.5$ and 0.8 , respectively representing the dividing points of low degree, moderate degree and high degree of coordination.

\section{The Moran Index Method Based on Spatial Analysis}

In order to comprehensively analyze overall correlation degree and the specific distribution about its spatial agglomeration of ecology-agricultureurban space evaluation unit, this paper makes a spatial autocorrelation analysis on the coupling and coordinated development of ecology-agriculture-urban space in Tacheng Basin.

$$
I=\frac{n}{\sum_{i=1}^{n} \sum_{j=1}^{n} W_{i j}} \times \frac{\sum_{i=1}^{n} \sum_{i=1}^{n} W_{i j}\left(x_{i}-\bar{x}\right)\left(x_{j}-\bar{x}\right)}{\sum_{i=1}^{n}\left(x_{i}-\bar{x}\right)^{2}}
$$

$$
\begin{gathered}
Z=\frac{I-E(I)}{\sqrt{\operatorname{VAR}(I)}} \operatorname{VAR}(I)=\sum_{j}\left(x_{j}-\bar{x}\right) / n \\
I_{i}=\frac{\left(x_{i}-\bar{x}\right)}{\operatorname{VAR}(I)} \sum_{j}\left[W_{i j}\left(x_{j}-\bar{x}\right)\right]
\end{gathered}
$$

...where $\mathrm{I}$ is global Moran index; $\mathrm{x}_{\mathrm{i}}$ and $\mathrm{x}_{\mathrm{j}}$ are respectively observed values of spatial units $\mathrm{i}$ and $\mathrm{j}$; $\bar{x}$ is the average value of observation values composed of $\mathrm{n}$ evaluation units; $\mathrm{W}_{\mathrm{ij}}$ represents spatial weight matrix of each evaluation unit $i$ and $j$, which is automatically generated by ArcGIS 10.2 after setting up parameters; $\mathrm{Z}$ is the threshold of standardized statistics; $\mathrm{E}(\mathrm{I})$ is the expected value of the autocorrelation of observed values; VAR(I) is the variance; $I_{i}$ stands for local Moran index; and $n$ is the total number of evaluation units.

\section{Operational Procedures}

Firstly, the study, taking 141 towns (townships) as the basic research unit, built a coordination degree index system (24 variables) and used the factor analysis method to determine the weights by SPSS 18.0 (IBM SPSS Statistics v18.0). Secondly, the final factor scores of ecological space, agricultural space and urban space were put into formula (3.4) and (3.5) to calculate the coupling degree coefficient (C) and coordinated development degree coefficient (D) of each evaluation unit in Tacheng Basin. Based on the relevant research results of existing scholars [30, 31], we made the grading standards of the coupling coordination degree in this paper (Table 2); thirdly, with the comparative analysis of ecology-agriculture-urban space utilization coordination level between 2008 and 2018, then the comparison figures of coordinated development level were obtained by ArcGIS 10.2; finally, based on the results of spatial coordination development degree in 2018, we analyzed spatial utilization characteristics and problems of Tacheng Basin using spatial autocorrelation (Moran's I).

Table 2. Grading standard of coupling coordination degree on ecology-agriculture-urban space.

\begin{tabular}{|c|c|c|c|}
\hline $\begin{array}{c}\text { The coupling degree } \\
\text { coefficient }(\mathrm{C})\end{array}$ & Types of coupling degree & $\begin{array}{c}\text { The coordinated development } \\
\text { degree coefficient }(\mathrm{D})\end{array}$ & Types of coordination degree \\
\hline \multirow{2}{*}{$\mathrm{C}<0.5$} & Not coordination & $0 \leq \mathrm{D}<0.2$ & Potentially dangerous stage \\
\cline { 3 - 4 } & Not coordination fundamentally & $0.2 \leq \mathrm{D}<0.4$ & Low-level coordination stage \\
\hline $0.5 \leq \mathrm{C}<0.8$ & Coordination fundamentally & $0.4 \leq \mathrm{D}<0.5$ & Antagonistic stage \\
\hline $0.8 \leq \mathrm{C}<0.9$ & Coordination & $\mathrm{D} \geq 0.8$ & Stepwise break-in stage \\
\hline $\mathrm{C} \geq 0.9$ & & Coordinate development stage \\
\hline
\end{tabular}




\section{Results and Discussion}

\section{Comparison of Coordinate Development Levels}

As shown in Fig. 2, the coefficient of coordination degree was classified into four groups, and the comparison results in 2008 and 2018 illustrate that the coordination level of ecology-agriculture-urban space has been improved to some extent in the past decade, which is closely related to the economic development level of Tacheng Basin. Under the guidance of the ecology-agriculture-urban spatial pattern, there
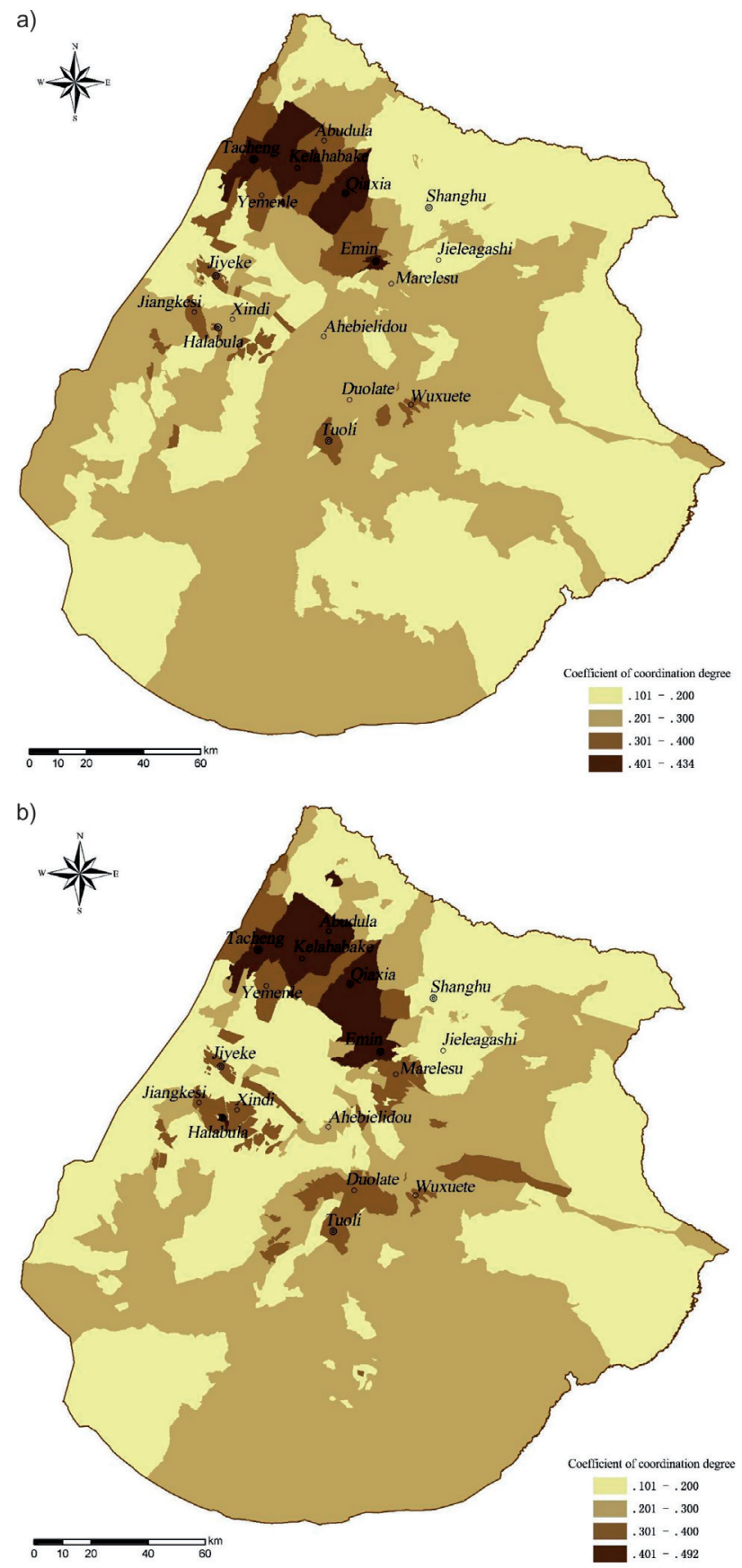

Fig. 2. Coordination development coefficient of 141 evaluation units in: a) 2008 and b) 2018 . exist some disparities between 2008 and 2018. The coordinated degree of Tacheng is 0.434 in 2008 and it increases to 0.492 in 2018 and that of Emin town, which increased from 0.410 to 0.482 . Additionally, the level of coordinated development of Halabula, Ergong, Duolate, etc., has been improved to some extent. However, it is still at a low level as a whole. According to the grading standard of the coupling coordination degree in this paper [32, 33], most towns (townships) of ecology-agriculture-urban space were in the stage of low-level coupling and coordination development, and few were in the stage of antagonism. In some areas, such as Kulusitai Grassland, some grassland areas, etc., the coordination level is from low-level coordination stage to potentially dangerous stage especially Chahantuohai Grassland, whose coefficient of coordinated development was reduced from 0.279 to 0.101 . Areas with lower coordinated development degree highlight the function of ecological fragility and protection.

In 2018, the evaluation units with a higher degree of coordinated development are mainly on both sides of the county road and provincial road, which includes the towns of Ergong, Qiaxia, Emin, etc. In recent years, the economies of Ergong and Qiaxia have developed rapidly with convenient transportation as the administrative town in Tacheng. For Emin, the relatively perfect infrastructure construction has played a decisive role in driving local economic growth, and agricultural production, urban development and ecological protection are relatively synchronous. Areas with low level of coordinated development include the Emin River, the core area of Kulusitai Grassland, part of the pasture, and so on. Increasing agricultural water use upstream and the serious overexploitation of groundwater have caused downstream dual utilization conflicts of water quantity and quality. Grassland degradation, soil desertification and salinization have become more and more serious, aggravating the deterioration of the watershed ecosystem year by year. The disordered development of agriculture and the imbalance of grass and livestock further destroy ecological balance of grassland, which leads to uncoordinated development of ecological space and agricultural space. The natural environment sensitivity of forest farm and grassland in each township is high, mainly for ecological protection, which is relatively weak in the function of agriculture and urban space.

\section{Spatial Distribution Features}

The results showed that the global Moran index was 0.139264 and p-value was 0.021692 (Table 3), which indicated that there was a possibility of more than $95 \%$ positive spatial correlation according to the threshold set by Ronald Aylmer Fisher (Table 4). Therefore, the coupling and coordinated development degree of ecology-agriculture-urban space presented a centralized distribution, which showed a similar agglomeration 
feature about the coordinated development of ecology-agriculture-urban space utilization. Through the analysis of Local Moran Index on the basis of constructing spatial weight matrix, Fig. 3 clearly showed that there only were three types of agglomeration states of ecology-agriculture-urban space: $\mathrm{HH}, \mathrm{LH}$ and LL (NN means there is no correlation). Highhigh concentration areas (HH) are mainly distributed in Ergong Town, Qiaxia Town, Kalahabake Township, Emin Town, Jiaoqu Township, etc., which are located at the intersection of S201 and S222, indicating that the coordinated development level of ecology-agricultureurban space is highly dependent on the comprehensive development of political, economic and transportation infrastructure. The low-high value (LH) appears in Yemenle, Abudula, Shanghu, Erdaoqiao, and so on, explaining that the coordinated development level of this area is affected by the development of surrounding areas. Furthermore, low-low (LL) are distributed in three clusters: one is in the northeastern part of the Basin, and due to ecological protection requirements the main development direction under the control of the artificial factor, agricultural and urban space function is weak. The second is located in Duolate and Wuxuete Townships; the third is in Jianggesi, Xindi and Aletengyemule Townships, in which crop cultivation is single and small in scale, the agricultural foundation is weak, and supporting facilities are not perfect, leading to ecological and agricultural sustainable development that is seriously challenged due to the poor natural conditions and traffic conditions.

Based on the status quo and the suitability evaluation results about ecological space, agricultural space and urban space, there mainly exist the following problems in ecology-agriculture-urban space development of Tacheng Basin. First of all, its ecological background

Table 3. Dividing standards of P-value and Z-score.

\begin{tabular}{|c|c|c|}
\hline $\begin{array}{c}\text { Z-Score } \\
\text { (Standard deviation) }\end{array}$ & $\begin{array}{c}\text { P-Value } \\
\text { (Probability) }\end{array}$ & Confidence \\
\hline$<-1.65$ or $>+1.65$ & $<0.10$ & $90 \%$ \\
\hline$<-1.96$ or $>+1.96$ & $<0.05$ & $95 \%$ \\
\hline$<-2.58$ or $>+2.58$ & $<0.01$ & $99 \%$ \\
\hline
\end{tabular}

Table 4. Moran I index of coupling coordination development in Tacheng Basin.

\begin{tabular}{|c|c|}
\hline \multicolumn{2}{|c|}{ Global Moran's I Summary } \\
\hline Moran's Index: & 0.139264 \\
\hline Expected Index: & -0.014695 \\
\hline Variance: & 0.004651 \\
\hline z-score: & 3.488205 \\
\hline p-value: & 0.021692 \\
\hline
\end{tabular}

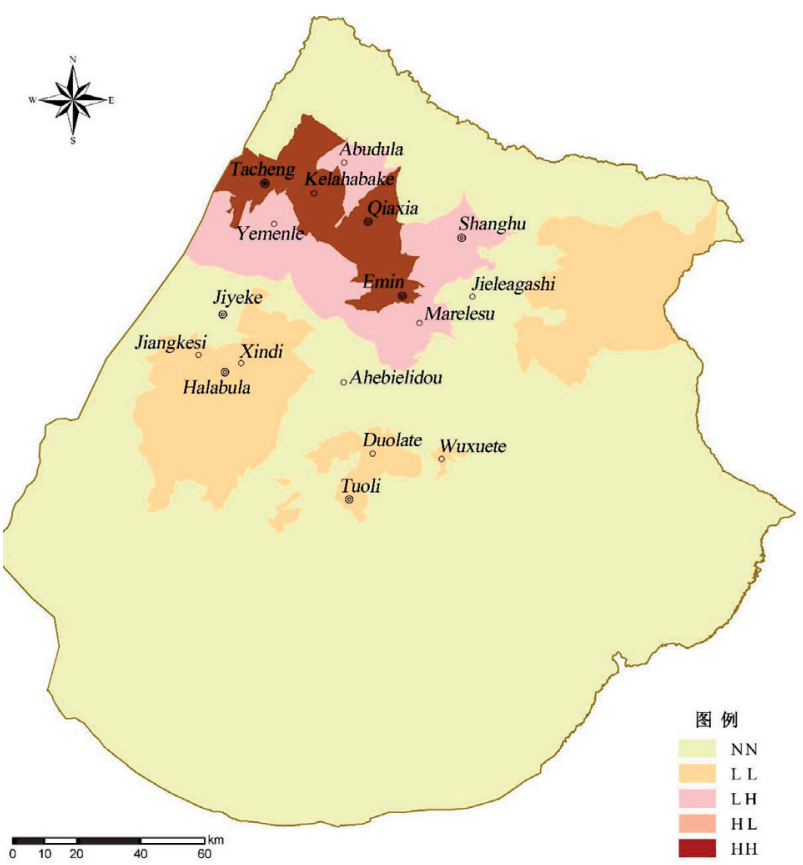

Fig. 3. Spatial analysis results based on Local Moran Index of Tacheng Basin.

is relatively fragile and sensitive, so it is difficult to resist inevitable natural disasters and high-intensity interference of human activities, and the ecological compensation mechanism is not perfect, which leads to the imbalance of the ecosystem. Secondly, the foundation of agricultural development is relatively weak and the overall industrial hierarchy is low, which is lack of core competitiveness, and that urbanization process is relatively slow. Thirdly, in the process of land reclamation, large areas of grassland were turned into cultivated land. Due to disordered expansion of agricultural production space, the change of spatial pattern, and the disorder of ecological supervision order, ecological space has been seriously damaged, affecting the economic development of Tacheng Basin, which has led to an ecology-agriculture-urban space lack of collaborative development strategy. Finally, there is no unified management organization and overall management measures in Tacheng Basin, which is difficult for operation and coordination between departments, and the degree of connection is low, leading directly to a chaotic situation.

However, the ecology-agriculture-urban space of key ecological function areas still has greater development potential. Ecological space, agricultural space and urban space are interconnected and interact with each other, but the emphasis on development direction is different with respective characteristic resources. There are rich, high-quality and unique natural and cultural resources in Tacheng Basin, mainly including natural scenery, folk customs, grassland and wetland tourism, border culture and so on. On the premise of not destroying the ecological balance, we should fully exploit its ecological value, transform its resource advantages into industrial 
advantages, and develop ecological tourism with great potential. The green and ecological agricultural product market of agricultural space has a broad prospect, but it cannot occupy ecological function space. In addition, it is the premise of ecological protection to promote new urbanization construction in the basin.

\section{Policy Implications}

An orderly and reasonable space pattern cannot be separated from government supervision and leadership. Regional interconnected and integration development is an effective way to realize coordinated development of ecology-agriculture-urban space. The space dominated by ecological functions includes smallscale agricultural production and residential areas, and ecological protection should be given priority in the agricultural production space. Similarly, there will also be agricultural production, protection of basic farmland and improvement of ecological environment in urban space. So only through vertical linkage and horizontal integration can orderly, coordinated and sustainable development of the ecology-agriculture-urban space be effectively realized. The policy suggestions are proposed as follows.

From the perspective of ecological protection, it is important for government to formulate diversified and targeted ecological compensation policies. Firstly, relevant contents of compensation policies should be further detailed, and long-term plans should be made about compensation methods, compensation amount, compensation time and compensation objects. Secondly, the compensation standards vary from district to district with different compensation measures. Compared with Tacheng and Emin, Tuoli and Yumin have a relatively weak economy with serious ecological damage, so their compensation standards should be appropriately improved, and at the same time compensation measures for returning farmland to grass, prohibiting graze and rest grazing should be further optimized. Finally, provide diversified forms of compensation, such as cash and in-kind compensation, technology and policy compensation, strengthen the financial fund transfer, and gradually compensate for the financial gap caused by the restoration of ecological problems and guarantee of ecological security of the ecological functional areas, with the purpose of ensuring orderly production and living of herdsmen and fundamentally improve their own development.

From the perspective of economic transformation, it should promote the development of ecological agriculture and characteristic industry to improve the economic level, breaking the low level of coordinated development. Therefore, making use of and integrating the ecological resources of Kulusitai Prairie to fully exploit the functions in ecology, tourism, leisure and education, and then develop grassland tourism and related services, fundamentally realizing the coupling and coordination between income increase for farmers and ecological protection based on the "green passage" at the port of Baketu in order to create an international agricultural products trading platform in the basin and build a green food processing and distribution base facing central Asia. In addition, relying on a development strategy of building Xinjiang into a "logistics center" - the western fulcrum of the " $T$ platform" in "business logistics center" - will be built.

From the perspective of regional division and cooperation for building a reasonable spatial pattern of inward and outward connection to develop an exportoriented economy with the advantage of strategic position on the silk road, it is necessary to combine the basin's green resources with a good industrial base and information condition of Kelamayi, which makes the Tacheng Basin become its agricultural and animal husbandry products base and ecological leisure tourism area, so as to promote the formation of a complementary industrial spatial layout with Kelamayi. In addition, the four counties and cities of Tacheng Basin should strengthen the cooperation with the corps, integrate industrial resources and ecological resources across regions, and reduce redundant construction and disorderly competition to form a clear industrial spatial pattern of open platforms, industrial parks, planting and breeding bases and ecological barriers.

\section{Conclusions}

From a new perspective of ecology-agricultureurban space, this study made dynamic comparative analysis of the coordinated development level between 2008 and 2018 in Tacheng Basin and explored spatial utilization characteristics and existing contradictions, which scientifically illustrated that the coordinated development degree of ecology-agriculture-urban space is directly proportional to the level of economy and infrastructure such as transportation, and will be getting close to stepwise break-in stage $(0.5 \leq \mathrm{D}<0.8)$ with the excavation of the ecological economy. The new idea can be applied to all similar key ecological function areas (the typical ecological areas with prominent contradictions between ecology and the economy) and provide scientific evidence for analyzing the spatial distribution characteristics and conflict problems, which should be of primary interest in future research.

The research results in this paper also indicated that the ecology-agriculture-urban functional space of key ecological function areas is a complex space with interrelation, mutual influence and staggered distribution. There are abundant ecological resources, favorable eco-environment and greater ecological value in such areas, but a lack of impetus to promote economic development and transformation. Therefore, aiming at those contradictory problems, this study proposed corresponding measures that can offer a scientific reference for macro decision-making, promote the development of characteristic industry and economic 
transformation, and improve the relevant supporting facilities and orderly solve the contradiction of ecologyagriculture-urban space, thus breaking the bottleneck of low-level development and achieving optimization of ecological environment, enhance the level of industry development and improve living quality.

In addition, the ecological background of key ecological function areas is relatively fragile and sensitive. It is necessary to further improve the ecological compensation mechanism and raise the level of ecological development, achieving coordinated and sustainable development of ecology-agriculture-urban space in key ecological function areas. As the decisionmaker and leader, how the government will do this is a scientific problem worth discussing and studying in future research.

\section{Acknowledgements}

This study was financed by the Grant Program of the Youth Project of Jiangsu Natural Science Foundation (BK20170440), Jiangsu Natural Science Foundation (BK20181105), the autonomous deployment project of Nanjing Institute of Geography and Limnology, CAS (NIGLAS2017QD12), the Strategic Priority Research Program A of the Chinese Academy of Sciences (XDA20010301) and the National Key R\&D Program of China (2018YFD1100101).

\section{Conflict of Interest}

The authors declare no conflict of interest.

\section{References}

1. XIONG S.G., WAN J., YU X.Y., DENG B., ZHENG W.W. Research on the Route of Advancing Environmental Protection and Poverty Alleviation Cooperatively in the National Key Ecological Function Areas - A Case Study of Zigui, the national Poverty County. Environment and sustainable development, 41 (3), 9, 2016.

2. LI B.L., YUAN Y.C., GAO X.Z., Xu L.L. Major Issues and Countermeasures of Eco-environmental Protection of the National Key Ecological Function Areas. Environmental Protection, 12, 15, 2014.

3. WU J., GONG Y.Z., ZHOU J.B., WANG X.X., GAO J.X., A Y. The Governance of Integrated Ecosystem Management in Ecological Function Conservation Areas in China. Regional Environmental change, 13 (6), 1302, 2013.

4. FU B.J., YU D.D., LV N. An Indicator System for Biodiversity and Ecosystem Services Evaluation in China. Acta Ecologica Sinica, 37 (2), 341, 2017.

5. SI J.N. Three strategic frameworks for building functional zones. China Industry News, 2011-06-16(A02).

6. LI Z.R. Provide surveying and mapping geographic information service for the compilation of the $13^{\text {th }}$ fiveyear plan -analyzing the results of three spatial divisions of cities and counties. China Surveying and Mapping, 6, 41, 2015.

7. ZHENG M.B., DAI Z., ZHOU J.N. Study on Boundary Demarcation Method of Urban Space, Agricultural Space and Ecological Space Based on "Multiple rules in one". Intelligent City, 8, 156, 2017.

8. WANG G.L., YANG D.G., XIA F.Q., ZHONG R.S., XIONG C.H. Three Types of Spatial Function Zoning in Key Ecological Function Areas Based on Ecological and Economic Coordinated Development: A Case Study of Tacheng Basin, China[J]. 29 (4), 690, 2019.

9. VIEGAS M., ANTUNES M. Convergence in the Spanish and Portuguese NUTS 3 Region: An Exploratory Spatial Approach. Intereconomics, 48 (1),66, 2013.

10. CHEN W.Y. Urban Area, Agricultural Area and Ecological Area's Space Identity and Spatial Pattern of Xishui County. Central China Normal University, 2018.

11. LEI X. Analysis on the Urbanization of Key Ecological Function Area -A Case Study on Tibetan Areas of Sichuan // Proceedings of the $20^{\text {th }}$ International Symposium on Advancement of Construction Management and Real Estate. Springer Singapore, 2017.

12. LI Y.Q., LU C.X., DENG O., CHEN P.P. Ecological Characteristics of China's Key Ecological Function Areas. Journal of Resources and Ecology, 6 (6), 429, 2015.

13. CHEN Q., ZHOU Z.F., YAN L.H. The Evaluation of Ecological Civilization Construction of the National Key Ecological Function Areas - A Case Study in Libo County, Guizhou Province. Chinese Journal of Agricultural Resources and Regional Planning, 37 (9), 2, 2016.

14. CHI Y.Y., RAO S., LU J. A Preliminary Study on Ecological Security Assessment Methods for Important Ecological Function Areas - A Case Study in Desertification Control Regions. Resources Science, 32 (5), 808, 2010.

15. XIAO Y., ZHANG C.S., XU J. Areas Benefiting from Water Conservation in Key Ecological Function Areas in China. Journal of Resources and Ecology, 6 (6), 376, 2015.

16. HAN G., BO P., XIA H J. The Discussion on the Influence to Biological in Ecological Function Areas by PlanningTake the Example of Xingan Mountains Ecological Function Areas. Applied Mechanics and Materials, 360, 2133, 2013.

17. CHEN Z.C. Study on Economic Effects of Ecological Compensation of Key Ecological Functional Areas in Xinjiang. Journal of Southwest Minzu University (Humanities and Social Science), 6, 167, 2015.

18. ZHANG Y.R., XIANG P.A. Selection of Advantageous Industries with Regional Features in Key Ecological Function Areas - Taking Zhangjiajie City as A Case. Crop Research, 32 (5), 427, 2018.

19. SHAO Q.Q., CAO W., FAN J.W., HUANG L., XU X.L. Assessment on the Effects of the First-stage Ecological Conservation and Restoration Project in Sanjiangyuan Region. Journal of Geographical Sciences, 71 (2), 4, 2017.

20. FARHAN Y., NAWAISEH S. Spatial Assessment of Soil Erosion Risk Using RUSLE and GIS Techniques. Environmental Earth Sciences, 74 (6), 2, 2015.

21. LIU L.L., CAO W., WU D., HUANG L. Temporal and Spatial Variations of Ecosystem Services in National Key Ecological Function Zones. Geographical Science, 38 (9), 1509, 2018

22. FARNWORTH E.G., GOLLEY F.B. Evaluation of Research and Applications in the Neotropics; A Report of the Institute of Ecology (TIE). Quarterly Review of Biology, 139 (5), 649, 1976. 
23. PETROSILlO I., ZURLINI G., GRATO E., ZACCARELLI N. Indicating fragility of socio-ecological tourism-based systems. Ecological Indicators, 6 (1), 108, 2006.

24. STEPHEN. Health Workforce Planning and Innovations in Service Delivery. Brain Research, 348 (1), 205, 2013.

25. CARRANZA T., MANICA A., KAPOS V., BALMFORD A. Mismatches between Conservation Outcomes and Management Evaluation in Protected Areas: A Case Study in the Brazilian Cerrado. Biological Conservation. 173 (8), 13, 2014.

26. BARAL N., DHUNGANA A. Diversifying Finance Mechanisms for Protected Areas Capitalizing on Untapped Revenues. Forest Policy \& Economics, 41 (3), 63, 2014.

27. MARTIN R.C. Federal Regional Development Programs and U.S. Problem Areas. Journal of Regional Science. 19 (2), 158, 1979.

28. CHENG H., XU Q., GUO Y.Q. Temporal and Spatial Evolution of the Coupling Coordinated Development between Tourism Resources Development and Ecological Environment in China. Economic Geography, 39 (7), 235, 2019.
29. MA F., REN F.X., YUEN K.F., GUO Y.R. The Spatial Coupling Effect between Urban Public Transport and Commercial Complexes: A Network Centrality Perspective. Sustainable Cities and Society, 50, 4, 2019.

30. WEI X.X., ZHAO J., WEI W., XIE B.B. Coordinated Development of Ecological-economic System and Spatial Evolution Based on County Unit in China. Progress in Geography, 33 (11), 1537, 2014.

31. PENG J.Z., LUO Y., DENG W., HUANG X. Coordinate Development Evaluation among Industry Transfer, Professional Market and Urbanization with Chinese Characteristics. Economic Geography, 33 (12), 58, 2013.

32. ZHAO G.S., LIU J.Y., KUANG W.H., OUYANG Z.Y., XIE Z.L. Disturbance Impacts of Land Use Change on Biodiversity Conservation Priority Areas across China: 1990-2010. Journal of Geographical Science, 25 (5), 516, 2015.

33. LU H., ZHANG Y., ZHENG W.S. Evaluation on Spatio-temporal Development and Interaction of Intensive Urban Land Use and Urbanization - Case Studies of the Cities in the Bohai Rim Region. Geographical Research, 30 (10), 1806, 2011. 